\title{
Multiple paternity and complex fertilisation dynamics in the squid Loligo vulgaris reynaudii
}

\author{
Paul W. Shaw ${ }^{1, *}$, Warwick H. H. Sauer ${ }^{2}$ \\ ${ }^{1}$ School of Biological Sciences, Royal Holloway, University of London, Egham, Surrey TW20 0EX, UK \\ ${ }^{2}$ Department of Ichthyology \& Fisheries Science, Rhodes University, PO Box 94, 6140 Grahamstown, South Africa
}

\begin{abstract}
Predictions regarding multiple paternity and male mating competition in the squid Loligo vulgaris reynaudii D'Orbigny, based upon behavioural observations, were tested by DNA fingerprinting of offspring within wild caught egg strings along with putative female and male parents. Results confirm that the potential for multiple mating by females does translate into multiple paternity within broods, at least in some instances, with up to 4 or 5 males gaining fertilisations. Patterns of fertilisation success within egg strings demonstrated distinctly different levels of success by males, both within the brood as a whole but also along the length of a string. These preliminary results confirm an emerging picture of complex genetic mating systems in squid, and suggest the action of intricate patterns of sperm competition and the possibility of cryptic female choice in this species.
\end{abstract}

KEY WORDS: Loligo $\cdot$ Squid $\cdot$ Microsatellites $\cdot$ Multiple paternity $\cdot$ Sperm competition $\cdot$ Fertilisation

\section{INTRODUCTION}

Loliginid squids are important trophic components of many near-shore and continental shelf marine ecosystems, and also the target of valuable commercial fisheries (Caddy \& Rodhouse 1998). Heavy fishing pressure targeted on spawning aggregations of these approximately annual and semelparous species has led to concerns regarding effects on recruitment, and the need for better understanding of their reproductive biology (Boyle \& von Boletzky 1996, Hanlon 1998). Squid also display some of the most interesting and complex behavioural adaptations amongst marine invertebrates, particularly in respect to their mating strategies (Hanlon \& Messenger 1996), and therefore represent interesting candidates for study of the action and evolution of sexual selection and reproductive strategies.

The chokka squid Loligo vulgaris reynaudii D'Orbigny has been heavily exploited on its spawning grounds off the coast of South Africa since 1985 (Augustyn et al. 1994, Sauer 1995). Previous behavioural observations have shown that individuals engage in complex mating behaviours in mating are- nas situated over large communal spawning beds on the sea floor (Sauer \& Smale 1993, Sauer et al. 1997, Hanlon et al. 2002). Females arriving on the spawning grounds often have sperm present in a storage organ below the buccal mass. In addition, females commonly mate with multiple males over short time periods (hours), during which males deposit discrete packages of sperm (spermatophores) in the vicinity of the oviduct. Females pair up and mate in a parallel position with large males ('consorts'), who accompany and guard them until egg laying. Other large males may compete for females in agonistic bouts, sometimes displacing the 'consort' male, whereas small 'sneaker' males attempt extra-pair copulations using quick head-to-head matings, appearing to deposit spermatophores on the arms of the female. Studies of the congener $L$. pealei have demonstrated that parallel and head-to-head matings result in deposition of spermatophores in different positions on the female, around the oviduct or around the buccal mass and sperm storage organ respectively (Hanlon et al. 1997). Females attach single egg strings (each containing $\sim 100$ to 150 eggs) to the seabed, fertilising the eggs during laying with sperm from the storage organ or by 
breaking open spermatophores deposited on her mantle or buccal region by males. These behavioural dynamics indicate that females have access to sperm from different males and that multiple paternity within the offspring of individual females may be common. The potential for female choice, and both indirect (different male mating strategies) and direct sperm competition is also present.

The application of DNA markers in paternity testing has made significant contributions to resolving actual reproductive outcomes and fertilisation success of different mating strategies in a wide range of organisms (e.g. Birkhead \& Möller 1998, Avise 2001). Several studies have applied DNA fingerprinting methods to loliginid squid, and have established that multiple paternity is common within egg strings of both Loligo forbesi (Shaw \& Boyle 1997, Emery et al. 2001) and L. pealei (Buresch et al. 2001). These studies, however, employed genotyping of offspring within randomly collected egg strings, without access to known (or potential) parents or direct links with behavioural observations, therefore limiting the information that could be gained on outcomes of different male mating strategies. Although methods are being developed for reconstructing parental genotypes from full-/half-sib progeny arrays (see Emery et al. 2001), access to at least 1 parental genotype (in this case the female) and 1 or more of the competing sex (usually males) is still desirable for unambiguous determination of fertilisation success rates. For this reason, in the present study we attempted to collect egg strings of L. vulgaris reynaudii directly, during the spawning process, along with known females and consort males. The aim of this study was to assess, using DNA fingerprinting, whether: multiple paternity is a consequence of multiple mating observed in this species; fertilisation success by different males is equal and random or alternatively that some males sire more offspring than others; mate guarding by the consort male guarantees fertilisation success.

\section{MATERIALS AND METHODS}

Sample collection. Our aim was to collect mating squid pairs (female plus her 'consort' male) with a fertilised egg string produced by the female, to enable DNA fingerprinting of full-/half-sib offspring within a brood and comparison with the putative mother and consort male. Females extrude an egg capsule, containing up to 150 eggs, into their arms as they hover 2 to $3 \mathrm{~m}$ above the seabed, fertilising the eggs with stored sperm as they are extruded. Mating pairs were observed above an egg bed, and then the female and accompanying male were captured simultaneously as the female descended towards the egg bed to deposit her egg string. Samples of arm muscle were taken from the females and males and fixed in $90 \%$ ethanol. Egg strings were returned immediately to culture facilities, where they were maintained until the embryos had developed to a stage suitable for DNA extraction and genotyping, at which point they were fixed in $90 \%$ ethanol. Due to the extreme difficulty of performing such a method in the wild (samples were collected by SCUBA diving at 35-40 $\mathrm{m}$ depth), only 2 complete pairs plus egg string were collected, plus 2 further egg strings with the female only. A further 30 adults were collected from the area of the spawning ground to provide population estimates of genetic variability and allele frequencies. All samples were collected from spawning grounds of Loligo vulgaris reynaudii off the Eastern Cape coast of South Africa under licence (to W.H.H.Sauer) and in accordance with local rules on animal sampling.

Microsatellite DNA typing. Using a salting-out procedure (after Bruford et al. 1992), total DNA was extracted from tissue samples (arm tips) from all adults and whole embryos dissected out of egg strings. All individuals were genotyped at 4 microsatellite loci developed from the congener Loligo forbesi (Lfor1, Lfor3, Lfor5 and Lfor6; Shaw 1997). PCR reactions were performed under the following conditions: $120 \mathrm{~s}$ at $94^{\circ} \mathrm{C}$, then 30 cycles of $30 \mathrm{~s}$ at $92^{\circ} \mathrm{C}, 30 \mathrm{~s}$ at $45^{\circ} \mathrm{C}$ and $10 \mathrm{~s}$ at $72^{\circ} \mathrm{C}$, using a Hybaid Omnigene thermal cycler. Reaction mixes contained $20 \mathrm{ng}$ template DNA, $2.5 \mathrm{mM} \mathrm{MgCl}, 0.2 \mathrm{mM}$ of each nucleotide, $0.2 \mu \mathrm{M}$ of each primer (forward primer $5^{\prime}$ end-labelled with a Cy5 fluorescent dye group), 0.2 U Taq polymerase (Bioline UK) with the manufacturer's supplied $1 \times$ buffer (160 mM $\left(\mathrm{NH}_{4}\right)_{2} \mathrm{SO}_{4}, 670 \mathrm{mM}$ Tris-HCl), in a final reaction volume of $10 \mu \mathrm{l}$. Amplified products were resolved on $6 \%$ denaturing polyacrylamide gels run on an ALFexpress ${ }^{\text {TM }}$ (Pharmacia Biotech) automated sequencer, product sizes being determined against internal standard size markers using Fragment Manager v1.2 (Pharmacia Biotech).

Data analysis. For the randomly collected sample of adults, genotypes at all pairs of loci were tested for genotypic linkage disequilibrium, and within loci for deviation from Hardy-Weinberg expectations, using exact tests with significance determined by a Markov chain method (GENEPOP v3.2; Raymond \& Rousset 1995). None of the loci used exhibited linkage, and so can be used as independent markers for paternity assignment. Two loci (Lfor5 and Lfor6) did however display significant departures from Hardy-Weinberg equilibrium expectations, in both cases in the form of excess of homozygote genotypes. One possible explanation of such patterns is the presence of non-amplifying ('null') alleles, which was confirmed in this case by 
examination of brood-parent genotypes - absence of a maternal allele in brood members (female has null allele) and brood members homozygous for 1 maternal allele (i.e. also assumed to be a paternal allele) that never occurs in heterozygous state with the other maternal allele (father has null allele). Given at least 1 known parent (the mother in this case), correlation between alleles across multiple loci, and assuming standard Mendelian inheritance and segregation of alleles from parents to offspring, it is relatively easy to identify null alleles within genotypes, and therefore the null allele simply becomes an alternative allele for paternity assignment. All homozygote and non-amplifying (i.e. homozygous null) genotypes were checked by reamplification at least twice. For statistical purposes (see next paragraph), the frequency of the null allele (and therefore other allele frequencies) within the population was calculated using GENEPOP v3.2.

Determination of the occurrence of multiple paternity within broods (egg strings), the number of different males achieving fertilisations within broods, and the degree of fertilisation success of different males (relative proportion of brood sired) followed a number of steps. First, multiple paternity and the minimum number of males contributing to a brood was determined using the so-called 'single-locus method'. Maternal alleles are identified in each offspring at each locus, thereby identifying the paternal alleles in each offspring and therefore the number of different paternal alleles in each brood: multiple paternity can be deduced if more than 2 paternal alleles are found at any locus, and the minimum number of males is simply the maximum number of paternal alleles at any one locus divided by 2 (rounded up). Second, multiple paternity, minimum number of males and relative fertilisation success was determined using a multi-locus approach, whereby correlation of paternal (or maternal) alleles across multiple loci within individual offspring is used to reconstruct the paternal genotypes and therefore assign individual offspring to individual males (see DeWoody et al. 2000). The multi-locus method employs a parsimony-based approach that assumes Mendelian inheritance and segregation (each offspring receives 1 of 2 possible alleles from each of its mother and father), and attempts to find the minimum number of parental genotypes (a single mother plus ' $n$ ' fathers in the present case) that can logically explain allelic diversity and combinations within the observed progeny array. Outcomes of the parsimony approach were compared with those produced by a computation algorithm, GERUD1.0 (Jones 2001). GERUD also essentially uses the parsimony approach by computing (where the maternal genotype is known) all possible paternal multi-locus genotypes, determining the combinations of paternal genotypes able to explain the off- spring array using the minimum number of fathers, and then ranking the likelihood of paternal genotype combinations (if more than 1 unique solution is possible) according to a statistic combining fits of paternal alleles to a 1:1 segregation ratio within the brood, with the expected frequencies of the male genotypes given population allele frequencies.

Using the most likely, and conservative, outcome for the paternal genotypes contributing to the offspring array from each egg string, individual offspring were assigned to males. Where more than 1 male contributed to the array, relative fertilisation success was determined and tested for departure from an even ratio (i.e. some males are more successful than others). To test whether there were any differences in fertilisation success of different males along the length of an egg string, the positions of embryos were recorded as either lying in the proximal (i.e. near the attachment point of the string to the sea bed), middle or distal thirds of the string.

\section{RESULTS}

The number of alleles in the population sample of 36 adults was 20 at locus Lfor1, 16 at Lfor3, 30 at Lfor5 and 13 at Lfor6. Expected heterozygosities were $93.7 \%$ at Lfor1, 88.4\% at Lfor3, 92.6\% at Lfor5 and 71.6\% at Lfor6. Parental exclusion probabilities (with 1 parent known) for these loci, calculated in GERUD using equations from Dodds et al. (1996), were 0.845 for Lfor1, 0.747 for Lfor3, 0.835 for Lfor5, 0.525 for Lfor6 and 0.997 for all loci combined.

The 4 collected broods (egg strings) were successfully typed at all 4 microsatellite loci for 67 (String 1, with Female F1 plus Consort Male M1), 46 (String 2, with Female F2 plus Consort Male M2), 36 (String 3, with Female F3) and 71 (String 4, with Female F4) offspring. All offspring genotypes were consistent with the associated female genotype.

Using the 1-locus method, the minimum number of fathers estimated to contribute to the progeny arrays were: 4 in String 1 (maximum of 7 paternal alleles at Lfor3); 1 in String 2 (2 paternal alleles only at Lfor1, Lfor3, Lfor5 and Lfor6); 1 in String 3 (2 paternal alleles only at Lfor1, Lfor3, Lfor5 and Lfor6); and 4 in String 4 (7 paternal alleles at Lfor1, Lfor3 and Lfor5). Estimates of the minimum number of fathers produced by the multi-locus method agreed with the single-locus estimates for Strings 1, 2 and 3, but gave a higher number (5 males) for String 4 (see Table 1). The most parsimonious combination of multi-locus parental genotypes also agreed with 4 sires for String 1, 1 sire for each of Strings 2 and 3, and 5 sires for String 4. Parental multilocus genotype combinations produced by GERUD 
agreed with the deduced combinations for Strings 1, 2, 3 (1 unique combination each) and 4 (the most likely of 50 possible combinations), and assigned the same number of offspring to each of the deduced paternal genotypes.

Reconstruction of paternal genotypes indicated that Consort Male M1 sired the highest percentage (48\%) of offspring in String 1, with 3 unknown (i.e. unsampled) males siring 30\% (Male B), 18\% (Male C) and $4 \%$ (Male D) of the embryos (Table 1 ). The observed fertilisation success rates of the 4 males significantly differ from equality, whether male $\mathrm{D}$ is excluded $\left(\chi^{2}=\right.$ 9.51, $\mathrm{p}=0.0086)$ or not $\left(\chi^{2}=27.15, \mathrm{p} \ll 0.001\right)$. Table 1 also shows that the percentage of embryos sired by particular males varies from one end of the string to the other: Male M1 sired 90\% within the distal end but only $11 \%$ within the proximal end; Males B and C sired few embryos ( 5 and $0 \%$ ) within the distal end but large numbers (44 and $41 \%$ ) within the proximal end; Male D sired few offspring, evenly distributed. The skewed pattern of paternity along the string is significantly different from random expectations (assuming overall uneven siring frequencies by males), whether considered for each male separately $(\mathrm{M} 1 ; \mathrm{p}=0.0006 ; \mathrm{B}$;

Table 1. Loligo vulgaris reynaudii. Percentage of brood (\% per region) sired by different males in 4 egg strings, with an indication of variation in siring between different parts of the string: All: over whole string; P: proximal end; D: distal end; M: middle (see 'Materials and methods'); F1-F4: genotyped females; M1-M2: genotyped consort males of F1 and F2; B-P: reconstructed sire genotypes; $\mathrm{n}=$ number of embryos typed

\begin{tabular}{|c|c|c|c|c|}
\hline Sire & All & $P$ & M & $\mathrm{D}$ \\
\hline \multicolumn{5}{|c|}{ String 1 (F1 \& M1) } \\
\hline M1 & 48 & 11 & 53 & 90 \\
\hline B & 30 & 44 & 37 & 5 \\
\hline $\mathrm{C}$ & 18 & 41 & 5 & 0 \\
\hline $\mathrm{D}$ & 4 & 4 & 5 & 5 \\
\hline $\mathrm{n}$ & 67 & 27 & 19 & 21 \\
\hline \multicolumn{5}{|c|}{ String 2 (F2 \& M2) } \\
\hline M2 & 0 & 0 & & 0 \\
\hline E & 100 & 100 & & 100 \\
\hline $\mathrm{n}$ & 46 & 23 & & 23 \\
\hline \multicolumn{5}{|c|}{ String 3 (F3) } \\
\hline $\mathrm{G}$ & 100 & 100 & & 100 \\
\hline $\mathrm{n}$ & 36 & 18 & & 18 \\
\hline \multicolumn{5}{|c|}{ String 4 (F4) } \\
\hline $\mathrm{H}$ & 54 & 42 & 31 & 73 \\
\hline $\mathrm{J}$ & 20 & 18 & 31 & 17 \\
\hline K & 18 & 32 & 15 & 7 \\
\hline $\mathrm{N}$ & 7 & 4 & 23 & 3 \\
\hline $\mathrm{P}$ & 1 & 4 & 0 & 0 \\
\hline $\mathrm{n}$ & 71 & 28 & 13 & 30 \\
\hline
\end{tabular}

$\left.\mathrm{p}=0.0023 ; \mathrm{C}_{i} \mathrm{p}=0.0009\right)$, for all males between proximal and distal ends $\left(\chi^{2}=31.90, \mathrm{p} \ll 0.001\right)$ or over the whole string $\left(\chi^{2}=39.60, p=0.0017\right)$, or for the more successful males alone (M1-B, $\left.\chi^{2}=21.13, \mathrm{p} \ll 0.001\right)$. The distribution pattern of paternity of embryos is shown in Fig. 1.

Reconstruction of paternal genotypes indicated that a single male sired all offspring within String 2, but that this male was not the consort male (M2) associated with the female at the time of egg string deposition (Table 1). As only a single sire was detected within both proximal and distal ends of the string, embryos from the middle section were not typed.

Reconstruction of paternal genotypes indicated that a single male also sired all offspring within String 3 (Table 1). As only a single sire was detected within both proximal and distal ends of the string embryos from the middle section were not typed.

Reconstruction of paternal genotypes indicated that 1 male $(\mathrm{H})$ sired the majority (54\%) of offspring in String 4, with 4 further unsampled males siring $20 \%$ (Male J), 18\% (Male K), 7 \% (Male N) and 1\% (Male P) of the embryos (Table 1). The observed fertilisation
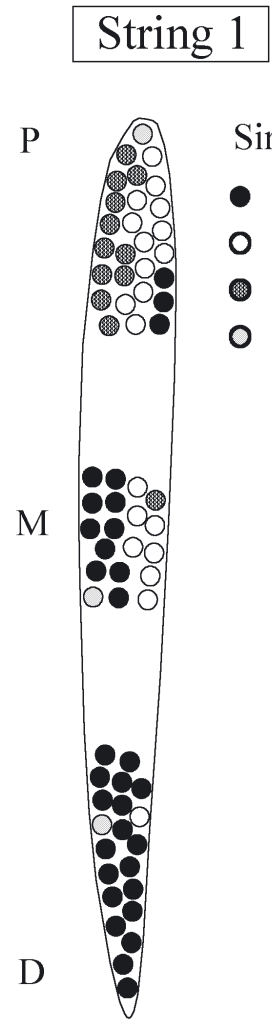

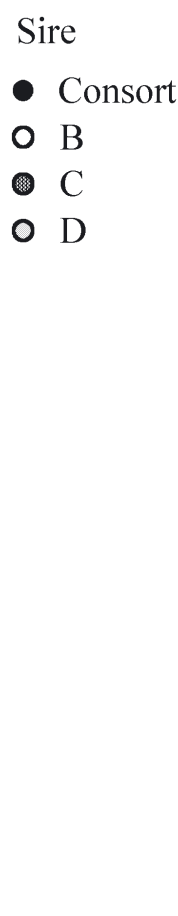

\section{String 4}

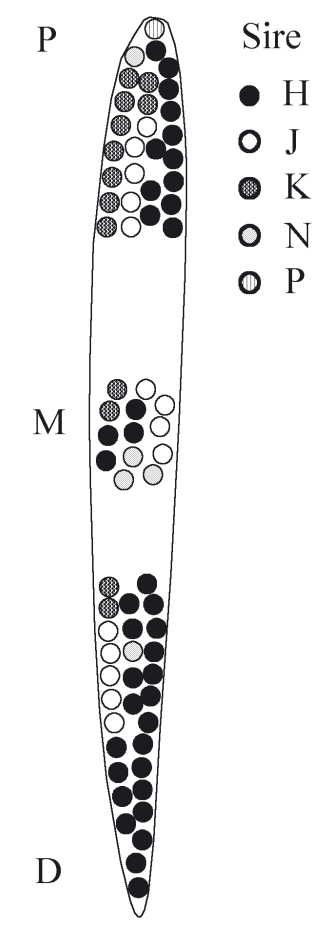

Fig. 1. Loligo vulgaris reynaudii. Distribution of embryos sired by different males within egg strings (embryo positions marked within areas are arbitrary: $\mathrm{P}=$ proximal $^{\mathrm{D}}=$ distal$_{\text {; }}$ $\mathrm{M}=$ middle) 
success rates of the 5 males significantly differ from equality, whether the two relatively unsuccessful males $\mathrm{N}$ and $\mathrm{P}$ are excluded $\left(\chi^{2}=18.46, \mathrm{p} \ll 0.001\right)$ or not $\left(\chi^{2}=58.22, \mathrm{p} \ll 0.001\right)$. As with String 1 , the percentage of embryos sired by particular males varies from one end of the string to the other: Male $\mathrm{H}$ sired $73 \%$ within the distal end but only $42 \%$ within the proximal end; Male K sired few embryos (7\%) within the distal end but larger numbers (32\%) within the proximal end; Males J and N show more even distributions over the whole string. The skewed pattern of paternity along the string is significantly different from random expectations for all males over the whole string $\left(\chi^{2}=24.35, p=0.0020\right)$, for the more successful males alone $\left(\mathrm{H}-\mathrm{K}, \chi^{2}=7.40, \mathrm{p}=0.0065 ; \mathrm{H}-\mathrm{J}-\mathrm{K}, \chi^{2}=\right.$ 8.85, $\mathrm{p}=0.0120)$ and for Male $\mathrm{K}(\mathrm{p}=0.0348)$, but not significant for all males between proximal and distal ends $\left(\chi^{2}=8.39, \mathrm{p}=0.078\right)$ and for Males $\mathrm{H}$ and $\mathrm{J}$ alone. The distribution pattern of paternity of embryos is shown in Fig. 1.

\section{DISCUSSION}

The results of paternity testing of egg strings of Loligo vulgaris reynaudii with 4 microsatellite loci, although preliminary in nature, demonstrate a complex mating system in this squid species with great potential for further study. Of the 4 broods typed, 2 were sired by a single male, whereas 2 were sired by 4 or 5 different males. These results confirm that the potential in $L$. vulgaris reynaudii for multiple mating by females does translate into multiple paternity within broods, at least in some instances. Multiple mating and paternity therefore appears to be a common strategy among loliginid squid, although whether L. vulgaris reynaudii differs from the other species studied to date (Shaw \& Boyle 1997, Buresch et al. 2001, Emery et al. 2001) in that it exhibits a substantial frequency of single paternity broods will require typing of many more broods to answer.

In the 2 broods (Strings 1 and 4) with multiple paternity, both exhibited significantly uneven distribution of fertilisation success among sires, with 1 male siring a clear majority of offspring, 1 or 2 further males siring substantial numbers of offspring, and a further 1 or 2 males siring very few offspring (Table 1, Fig. 1). It is interesting that a similar pattern has been observed in the previous studies of squid (Table 2): although based on small numbers of broods in all 3 cases, the average percentage of offspring sired by males (ranked according to success rates) falls into similar classes, with the most successful male siring $62-76 \%$, the 2 nd ranked male siring $23-25 \%$, the 3rd siring $5-18 \%$ and the 4 th siring $3-4 \%$. If such a pattern is confirmed by further testing, and is common to multiple species, what form of mating pattern or fertilisation dynamics could give rise to it? One hypothesis is that the successful sires represent the most recent matings in the parallel and head-to-head positions (with spermatophores deposited at the oviduct and sperm storage organ sites), with the possibility of a sneaker male becoming a third successful sire by adding his sperm to the mix during egg laying, and the low-success males representing small amounts of sperm still in the storage organ from previous mating/egg laying bouts. In String 1 the most successful male was the consort male, which might be predicted from previous behavioural observations (Hanlon et al. 1997, 2002): consort males appear to gain last-mate advantage, in that they are the last to mate with the female as they are usually successful in fighting off intruding males ('owner-advantage': Hanlon et al. 1997) until egg laying. If the most successful male $(\mathrm{H})$ in String 4 also can be concluded to be the consort male, based on the position of his offspring in the string (see next paragraph), then being a consort male may be providing last-mate precedence. Again, further tests will be required to confirm whether consort males regularly achieve most success. Another potential source of information to resolve this issue would be to genotype spermatophores remaining at different sites on the female after egg deposition, to assess if these represent single or multiple males and also if they correlate with paternity patterns in the egg strings.

The observation (String 2) of a consort male achieving no apparent fertilisation success is an intriguing

Table 2. Loligo spp. Average percentage (range) of embryos sired by ranked males within egg strings of 3 loliginid squid species. n: average number of embryos sampled per string; No. males: range in number of different males siring embryos within different strings. For L. forbesi, only average is given, as data are not thought to be independent (all strings presumed to be from 1 family: see Emery et al. 2001)

\begin{tabular}{|lccccccl|}
\hline Species & $\mathrm{n}$ & $\begin{array}{c}\text { 1st } \\
\text { male }\end{array}$ & $\begin{array}{c}\text { 2nd } \\
\text { male }\end{array}$ & $\begin{array}{c}\text { 3rd } \\
\text { male }\end{array}$ & $\begin{array}{c}4 \text { th } \\
\text { male }\end{array}$ & $\begin{array}{c}\text { No. } \\
\text { males }\end{array}$ & Source \\
\hline $\begin{array}{l}\text { L. vulgaris } \\
\text { reynaudii }\end{array}$ & 55 & $\begin{array}{c}75.5 \\
(48-100)\end{array}$ & $\begin{array}{c}25.0 \\
(20-30)\end{array}$ & $\begin{array}{c}18.0 \\
(18)\end{array}$ & $\begin{array}{c}4.0 \\
(1-7)\end{array}$ & $1-5$ & $\begin{array}{l}\text { Present } \\
\text { study }\end{array}$ \\
L. pealei & 43 & $\begin{array}{c}71.6 \\
(57-94)\end{array}$ & $\begin{array}{c}23.8 \\
(6-39)\end{array}$ & $\begin{array}{c}5.3 \\
(3-9)\end{array}$ & $\begin{array}{c}4.5 \\
(3-6)\end{array}$ & $2-4$ & $\begin{array}{l}\text { Buresch et } \\
\text { al. (2001) }\end{array}$ \\
& & & & & & & \\
L. forbesi & 90 & 61.6 & 23.2 & 11.9 & 3.3 & 4 & $\begin{array}{l}\text { Emery et al. } \\
(2001)\end{array}$ \\
\hline
\end{tabular}


one in relation to the above arguments. Video evidence (W. H. H. Sauer unpubl.) shows females continuing with egg strand deposition after an 'intruding' male has displaced the 'consort', with the intruder now seen guarding the female. As the female is still carrying the egg string (presumably inseminated prior to the intruding male appearing on the scene) in her arms during the agonistic bout between the males, she would either have to discard the egg case or continue with egg deposition. Should she choose the latter option, the intruding male may be 'forced' to guard her during egg strand deposition, presumably thereby gaining future mating access with her, even though he may not have contributed to the fertilisation of that egg string. Perhaps 'owner-advantage' (Hanlon et al. 1997) is worth waiting for?

The most intriguing observation in the present study is that in the 2 multi-sired broods, the distribution in the egg string of offspring sired by different males was not random. By far the majority of offspring within the distal end of the string (the end furthest from the attachment point in the sea bed) were sired by the most successful male, with few offspring sired by other males. In contrast, the proximal end of the string contained high frequencies (in 1 case the majority) of offspring sired by the other males. If this observation were to be confirmed by further testing it could indicate 1 of 2 main possibilities, bearing in mind that egg laying and fertilisation is separate from mating. First, a non-random pattern might result if sperm from different males is not mixed prior to use in fertilisation. This might occur if sperm are held in the storage organ in the order of mating, in a 'last in, first out' situation. Alternatively the different positions of the spermatophore deposition sites might influence release of sperm: the parallel-mated (usually the consort) male's spermatophores may be predominantly near the oviduct, where the egg string is extruded, whereas sneaker or previous mate's spermatophores may be predominantly near the storage organ/buccal mass, which is near to the arms where the egg string is held for some time prior to deposition on the sea bed. In such a situation, the non-random distribution of fertilisations can be viewed as a standard case of sperm competition (see Parker 1998), where males compete to place their spermatophores in the most effective sites (last in the storage organ, or near the oviduct). A further factor potentially influencing fertilisation dynamics is the complex construction of the loliginid egg string: eggs are embedded in a string of oviducal jelly, which is wrapped in a spiral configuration into layers of more dense jelly from the nidamental gland, all of which is encapsulated in a further jelly coat (see von Boletzky 1986). It is conceivable that the physical process of wrapping, extrusion and expansion (by hydration of the jelly coat) of the egg string may affect the insemination process, and therefore affect which parts of the egg string are penetrated by sperm from different sources. A second possibility is that sperm from different males are held at different sites on the female and that during extrusion of the egg string the female actively changes the source (site) of sperm used in fertilising the eggs, indicating that cryptic female mate choice (Eberhard 1996) is occurring in this squid. In Loligo vulgaris reynaudii, at least 2 methods of mating occur with 3 different placements of spermatophores (Hanlon et al. 2002). This may allow females to choose not only which consort males they adopt, but also which spermatophores they use during fertilisation. The initial evidence from this study, although largely circumstantial, does not contradict such a picture of behavioural complexity. Again, resolution of these interesting issues may be achieved by further testing of broods and genotyping of sperm and spermatophores from different sites on the female.

We have demonstrated that although difficult sampling is required, it is possible to provide estimates of mating success of male mating strategies in squid in the wild. This study also has uncovered interesting issues for further investigation regarding sperm competition and the potential for overt and cryptic female choice. Whatever the outcome of further studies, it is clear that loliginid squid have genetic mating systems with a complexity and versatility to match their behavioural dynamism.

Acknowledgements. This work was supported by the National Research Foundation (South Africa) and the South African Squid Management Industrial Association (grants to W.H.H.S.) and a RSF (Royal Holloway) grant to P.W.S. We thank Dr. M. Roberts (Chief Directorate, South African Department of Marine \& Coastal Management) for help with collecting samples.

\section{LITERATURE CITED}

Augustyn CJ, Lipinski MR, Sauer WHH, Roberts MJ, Mitchell-Innes BA (1994) Chokka squid on the Agulhas Bank: life history and ecology. S Afr J Mar Sci 90:143-154 Avise JC (ed) 2001 DNA-based profiling of genetic mating systems and reproductive behaviours in poikilothermic vertebrates. J Hered 92:99-211

Birkhead TRM, Möller AP (eds) (1998) Sperm competition and sexual selection. Academic Press, New York

Boletzky S von (1986) Encapsulation of cephalopod embryos: a search for functional correlations. Am Malacol Bull 4: 217-227

Boyle PR, Boletzky S von (1996) Cephalopod populations: definitions and dynamics. Phil Trans R Soc Lond B 351: 985-1002

Bruford MW, Hanotte O, Brookfield JFY, Burke T (1992) Single locus and multilocus DNA fingerprinting. In: Hoelzel AR (ed) Molecular genetic analysis of populations-a practical approach. IRL Press, Oxford, p 227-229 
Buresch KM, Hanlon RT, Maxwell MR, Ring S (2001) Microsatellite DNA markers indicate a high frequency of multiple paternity within individual field-collected egg capsules of the squid Loligo pealei. Mar Ecol Prog Ser 210: 161-165

Caddy JF, Rodhouse PG (1998) Cephalopod and groundfish landings: evidence for ecological change in global fisheries? Rev Fish Biol Fish 8:431-444

DeWoody JA, Walker D, Avise JC (2000) Genetic parentage in large half-sib clutches: theoretical estimates and empirical appraisals. Genetics 154:1907-1912

Dodds KG, Tate ML, McEwan JC, Crawford AM (1996) Exclusion probabilities for pedigree testing farm animals. Theoretical Appl Genet 92:966-975

Eberhard WG (1996) Female control: sexual selection by cryptic female choice. Princeton University Press, Princeton, NJ

Emery AM, Wilson IJ, Craig S, Boyle PR, Noble LR (2001) Assignment of paternity groups without access to parental genotypes: multiple mating and developmental plasticity in squid. Mol Ecol 10:1265-1278

Hanlon RT (1998) Mating systems and sexual selection in the squid Loligo: how might commercial fishing on spawning squid affect them? Calif Coop Ocean Fish Investig Rep 39: 92-100

Hanlon RT, Messenger JB (1996) Cephalopod behaviour. Cambridge University Press, Cambridge

Hanlon RT, Maxwell MR, Shashar N (1997) Behavioural dynamics that would lead to multiple paternity within egg capsules of the squid Loligo pealei. Biol Bull (Woods Hole) 193:212-214

Hanlon RT, Smale MJ, Sauer WHH (2002) The mating system

Editorial responsibility: Otto Kinne (Editor),

Oldendorf/Luhe, Germany of the squid Loligo vulgaris reynaudii (Cephalopoda, Mollusca) off South Africa: fighting, guarding, sneaking, mating and egg laying behavior. Bull Mar Sci 71:331-345

Jones AG (2001) GERUD 1.0: a computer program for the reconstruction of parental genotypes from progeny arrays using multilocus DNA data. Mol Ecol Notes 1:215-218

Parker GA (1998) Sperm competition and the evolution of ejaculates: towards a theory base. In: Birkhead TR, Møller AP (eds) Sperm competition and sexual selection. Academic Press, London, p 3-54

Raymond M, Rousset F (1995) Genepop (Version 1.2)population genetics software for exact tests and ecumenicism. J Hered 86:248-249

Sauer WHH (1995) South Africa's Tsitsikamma National Park as a protected breeding area for the commercially exploited chokka squid Loligo vulgaris reynaudii. S. Afr J Mar Sci 16:365-371

Sauer WHH, Smale MJ (1993) Spawning behaviour of Loligo vulgaris reynaudii in shallow coastal waters of the SouthEastern Cape, South Africa. In Okutani T, O'Dor RK, Kubodera T (eds) Recent advances in cephalopod fisheries biology. Tokai University Press, Tokyo, p 489-498

Sauer WHH, Roberts MJ, Lipinski MR, Smale MJ, Hanlon RT, Webber DM, O'Dor RK (1997) Choreography of the squid's 'nuptial dance'. Biol Bull (Woods Hole) 192:203-207

Shaw PW (1997) Polymorphic microsatellite markers in a cephalopod: the veined squid Loligo forbesi. Mol Ecol 6: 297-298

Shaw PW, Boyle PR (1997) Multiple paternity within the brood of single females of Loligo forbesi (Cephalopoda: Loliginidae), demonstrated with microsatellite DNA markers. Mar Ecol Prog Ser 160:279-282

Submitted: October 9, 2003; Accepted: January 27, 2004

Proofs received from author(s): March 22, 2004 